Article

\title{
Brain Distribution of Dual ABCB1/ABCG2 Substrates Is Unaltered in a Beta-Amyloidosis Mouse Model
}

\author{
Thomas Wanek ${ }^{1, *}$, Viktoria Zoufal ${ }^{1}$, Mirjam Brackhan ${ }^{2}$, Markus Krohn ${ }^{2} \oplus$, \\ Severin Mairinger ${ }^{1} \mathbb{D}$, Thomas Filip ${ }^{1}$, Michael Sauberer ${ }^{1}$, Johann Stanek ${ }^{1}$, Thomas Pekar ${ }^{3}$, \\ Jens Pahnke $2,4,5$ and Oliver Langer $1,6,7$ \\ 1 Preclinical Molecular Imaging, AIT Austrian Institute of Technology GmbH, 2444 Seibersdorf, Austria; \\ viktoria.zoufal@chello.at (V.Z.); Severin.Mairinger@chuv.ch (S.M.); thomas.filip@ait.ac.at (T.F.); \\ michael.sauberer@ait.ac.at (M.S.); johann.stanek@ait.ac.at (J.S.); oliver.langer@meduniwien.ac.at (O.L.) \\ Department of Neuro-/Pathology, University of Oslo (UiO) and Oslo University Hospital (OUS), \\ 0424 Oslo, Norway; mirjam.brackhan@medisin.uio.no (M.B.); markus.krohn@uni-luebeck.de (M.K.); \\ jens.pahnke@medisin.uio.no (J.P.) \\ 3 Biomedical Analytics, University of Applied Sciences Wiener Neustadt, 2700 Wiener Neustadt, Austria; \\ thomas.pekar@fhwn.ac.at \\ 4 LIED, University of Lübeck, 23562 Lübeck, Germany \\ 5 Department of Pharmacology, Faculty of Medicine, University of Latvia, 1586 Rīga, Latvia \\ 6 Department of Clinical Pharmacology, Medical University of Vienna, 1090 Vienna, Austria \\ 7 Department of Biomedical Imaging und Image-guided Therapy, Division of Nuclear Medicine, Medical \\ University of Vienna, 1090 Vienna, Austria \\ * Correspondence: thomas.wanek@ait.ac.at; Tel.: +43 (0)-505 50-3496
}

Received: 12 October 2020; Accepted: 28 October 2020; Published: 3 November 2020

\begin{abstract}
Background: ABCB1 (P-glycoprotein) and ABCG2 (breast cancer resistance protein) are co-localized at the blood-brain barrier (BBB), where they restrict the brain distribution of many different drugs. Moreover, $\mathrm{ABCB} 1$ and possibly ABCG2 play a role in Alzheimer's disease $(\mathrm{AD})$ by mediating the brain clearance of beta-amyloid $(\mathrm{A} \beta)$ across the BBB. This study aimed to compare the abundance and activity of ABCG2 in a commonly used $\beta$-amyloidosis mouse model (APP/PS1-21) with age-matched wild-type mice. Methods: The abundance of ABCG2 was assessed by semi-quantitative immunohistochemical analysis of brain slices of APP/PS1-21 and wild-type mice aged 6 months. Moreover, the brain distribution of two dual ABCB1/ABCG2 substrate radiotracers $\left(\left[{ }^{11} \mathrm{C}\right]\right.$ tariquidar and $\left[{ }^{11} \mathrm{C}\right]$ erlotinib) was assessed in APP/PS1-21 and wild-type mice with positron emission tomography (PET). $\left[{ }^{11} \mathrm{C}\right]$ Tariquidar PET scans were performed without and with partial inhibition of ABCG2 with Ko143, while [ ${ }^{11}$ C]erlotinib PET scans were only performed under baseline conditions. Results: Immunohistochemical analysis revealed a significant reduction (by 29-37\%) in the number of ABCG2-stained microvessels in the brains of APP/PS1-21 mice. Partial ABCG2 inhibition significantly increased the brain distribution of $\left[{ }^{11} \mathrm{C}\right]$ tariquidar in APP/PS1-21 and wild-type mice, but the brain distribution of $\left[{ }^{11} \mathrm{C}\right]$ tariquidar did not differ under both conditions between the two mouse strains. Similar results were obtained with $\left[{ }^{11} \mathrm{C}\right]$ erlotinib. Conclusions: Despite a reduction in the abundance of cerebral ABCG2 and ABCB1 in APP/PS1-21 mice, the brain distribution of two dual $A B C B 1 / A B C G 2$ substrates was unaltered. Our results suggest that the brain distribution of clinically used $A B C B 1 / A B C G 2$ substrate drugs may not differ between $A D$ patients and healthy people.
\end{abstract}

Keywords: ABCG2; ABCB1; blood-brain barrier; PET; Alzheimer's disease; beta-amyloid; tariquidar; erlotinib 


\section{Introduction}

The major pathohistological hallmarks of Alzheimer's disease (AD) are the accumulation of beta-amyloid $(\mathrm{A} \beta)$ plaques and neurofibrillary tangles consisting of hyperphosphorylated tau protein in the brain. It is believed that one of the underlying causes of this cerebral $A \beta$ accumulation is the impaired clearance of $A \beta$ peptides from the brain [1-3]. There are several different mechanisms for the removal of $A \beta$ peptides from the brain [4]; one important mechanism is its transport across the blood-brain barrier (BBB) into the blood. The adenosine triphosphate-binding cassette (ABC) transporter ABCB1 (also known as P-glycoprotein), which is expressed in the luminal (blood-facing) membrane of brain capillary endothelial cells, has been shown to work together with the low-density lipoprotein receptor-related protein 1 (LRP1) in the abluminal membrane of endothelial cells in translocating $A \beta$ peptides across the BBB [5-9]. There is evidence that the abundance and activity of ABCB1 are reduced in the brains of $A D$ patients relative to age-matched healthy control subjects [10-14]. Studies in $\beta$-amyloidosis mouse models indicated that the activity of cerebral ABCB1 can be pharmacologically induced (e.g., by treatment with pregnane $X$ receptor activators), leading to enhanced $A \beta$ clearance from the brain, which may constitute a potential therapeutic target in AD [8,15-18].

At the $\mathrm{BBB}, \mathrm{ABCB} 1$ is co-localized with $\mathrm{ABCG} 2$ (also known as breast cancer resistance protein). $\mathrm{ABCB} 1$ and $\mathrm{ABCG} 2$ have a largely overlapping substrate spectrum and act as highly efficient gate keepers in preventing the brain distribution of a range of different drugs, such as most currently known molecularly targeted anticancer drugs $[19,20]$. While the role of ABCB1 in mediating A $\beta$ clearance across the BBB has been thoroughly investigated [5-9,21], considerably less is known with respect to ABCG2. It has been shown that ABCG2 can also transport A $\beta$ peptides [22-24]. There are conflicting data regarding the abundance of $A B C G 2$ in the brains of $A D$ patients versus age-matched healthy controls. One study found an increase [22], another study a decrease [12] and four other studies found no changes in the abundance of ABCG2 in AD patients $[10,11,25,26]$. As the abundance of ABCG2 may not always correlate with its activity, it would be preferable to directly measure ABCG2 activity at the $\mathrm{BBB}$ of $\mathrm{AD}$ patients to further investigate the possible role of $A B C G 2$ in the brain clearance of $A \beta$.

Positron emission tomography (PET) imaging with radiolabeled transporter substrates has been proposed as a powerful method to measure the activity of $A B C B 1$ at the BBB $[13,14]$. While several effective PET tracers for ABCB1 have been described [27], ABCG2-selective PET tracers are currently not available. We have recently developed a PET protocol to measure ABCG2 activity at the mouse and human BBB [28-30]. This protocol is based on PET scans with the dual ABCB1/ABCG2 substrate $\left[{ }^{11} \mathrm{C}\right]$ tariquidar [31] under conditions of complete $\mathrm{ABCB} 1$ inhibition achieved by co-administration of unlabeled tariquidar [28-30]. In mice, the contribution of ABCG2 to the brain efflux of $\left[{ }^{11} \mathrm{C}\right]$ tariquidar can be revealed by administration of the ABCG2 inhibitor Ko143 [28,29].

In the present study, we first used immunohistochemistry to stain ABCG2 in the brains of a $\beta$-amyloidosis mouse model (APP/PS1-21) [32] and control mice (both aged 6 months), which revealed a significant reduction in ABCG2-stained microvessels in APP/PS1-21 mice. We then applied PET imaging to measure the consequences of the decreased abundance of cerebral ABCG2 on the brain distribution of two dual ABCB1/ABCG2 substrate radiotracers $\left(\left[{ }^{11} \mathrm{C}\right]\right.$ tariquidar and $\left[{ }^{11} \mathrm{C}\right]$ erlotinib) in APP/PS1-21 mice. The brain distribution of both radiotracers did not significantly differ between APP/PS1-21 mice and wild-type mice, suggesting that the observed reduction in cerebral ABCG2 abundance may not be sufficient to alter the brain distribution of ABCB1/ABCG2 substrate drugs.

\section{Results}

\subsection{Immunohistochemistry}

ABCG2 was immunohistochemically stained in brain slices of APP/PS1-21 mice and wild-type littermates aged 6 months ( $n=3$ per group) (Figure 1). For immunohistochemical analysis, we selected two brain regions in which $A \beta$ load was shown to be high in APP/PS1-21 mice at the investigated age (hippocampus and cortex) and one region with negligible $A \beta$ load (cerebellum) [33]. A semi-quantitative 
analysis of the stained microvessels indicated a significant decrease (by 29-37\%) in the number of ABCG2-stained microvessels in the hippocampus and cerebellum of APP/PS1-21 versus wild-type mice (Figure 2a,c), while no significant difference was found in the cortex (Figure 2b). This suggested that the reduction in the abundance of ABCG2 in APP/PS1-21 mice was independent of A $\beta$ deposition.
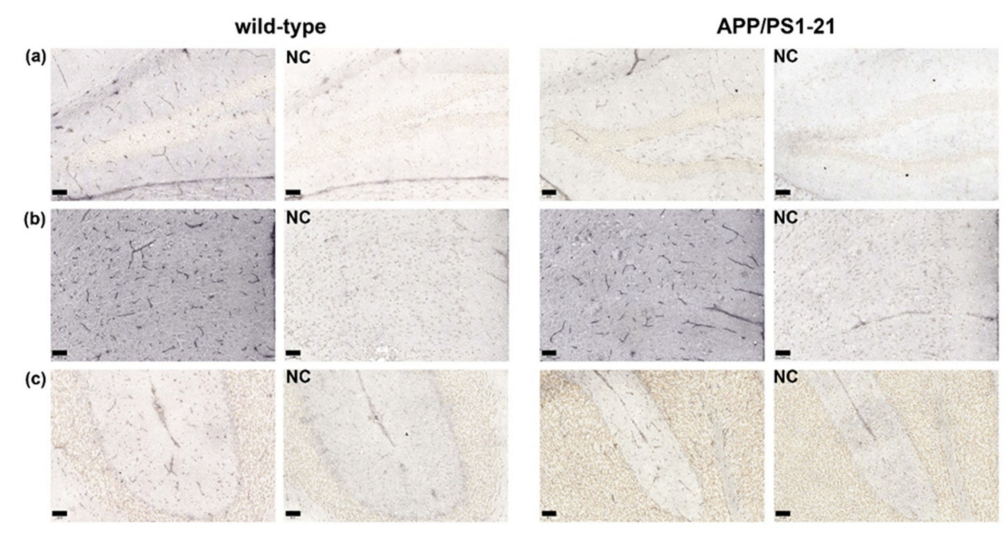

Figure 1. Examples of immunohistochemical staining of mouse ABCG2 in microvessels of 6-months-old wild type and APP/PS1-21 mice in (a) hippocampus (dentate gyrus), (b) cortex (cingulate cortex) and (c) cerebellum (4th and 5th cerebellar lobules with primary fissure) region. Enlarged areas are shown at 20× magnification. Scale bar in lower left indicates $50 \mu \mathrm{m}$. (NC, negative control: staining protocol without primary antibody).

(a)

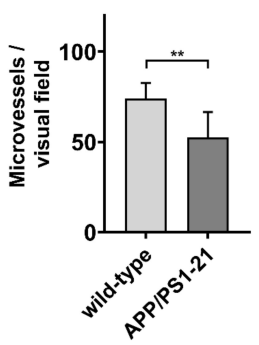

(b)

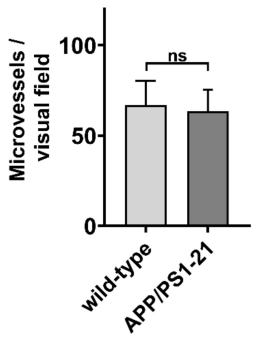

(c)

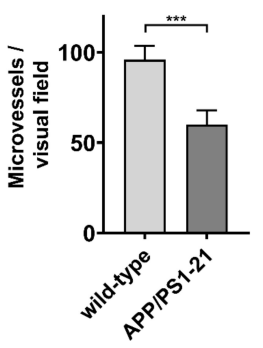

Figure 2. Semi-quantitative analysis of ABCG2-stained microvessels in (a) hippocampus, (b) cortex and (c) cerebellum of 6-months-old APP/PS1-21 mice and age-matched wild-type mice. For each region, the mean of four visual fields (at $20 \times$ digital magnification) per animal ( $n=3$ animals per strain) was used for statistical testing. Error bars indicate SD. (ns, not significant; ${ }^{* *} p<0.01 ; * * * p 0.001$; 2-sided $t$-test). 


\section{2. $\left[{ }^{11}\right.$ C]Tariquidar PET}

We used a previously developed PET protocol [28] which involved PET scans with the dual ABCB1/ABCG2 substrate $\left[{ }^{11} \mathrm{C}\right]$ tariquidar with co-administration of unlabeled tariquidar $(12 \mathrm{mg} / \mathrm{kg})$ to saturate cerebral $\mathrm{ABCB} 1$ activity and thereby selectively measure ABCG2 activity, without and with partial ABCG2 inhibition with the ABCG2 inhibitor Ko143 (5 mg/kg) [34]. PET summation images of $\left[{ }^{11} \mathrm{C}\right]$ tariquidar in APP/PS1-21 and wild-type mice are shown in Figure 3. Without Ko143 pretreatment, brain radioactivity concentrations in both mouse strains were markedly lower than in most of the surrounding head region, while in Ko143-treated animals, brain radioactivity concentrations approached the concentrations in the surrounding head region. The corresponding time-activity-curves (TACs) in whole brains are shown in Figure 4. In both mouse strains, mean TACs were higher under conditions of partial ABCG2 inhibition than under conditions without ABCG2 inhibition. Brain-to-plasma radioactivity concentration ratios $\left(K_{\mathrm{p}, \text { brain }}\right)$ were determined as a parameter for the brain distribution of $\left[{ }^{11} \mathrm{C}\right]$ tariquidar (i.e., the ratio of PET-derived radioactivity concentration at the last time point and the radioactivity concentration in plasma measured at the end of the PET scan) [28]. In Figure $5, K_{p}$,brain values are shown for the two mouse strains for the three examined brain regions (hippocampus, cortex and cerebellum) without and with ABCG2 inhibition. No significant differences in $K_{\mathrm{p}, \text { brain }}$ values were found between APP/PS1-21 and wild-type mice in any of the investigated brain regions, either for scans without or for scans with partial ABCG2 inhibition. For both mouse strains, $K_{\mathrm{p}, \text { brain }}$ values in the hippocampus and cortex were significantly higher after partial ABCG2 inhibition (Figure $5 \mathrm{a}, \mathrm{b}$ ). In the cerebellum, $K_{\mathrm{p} \text {,brain }}$ was only significantly increased after partial ABCG2 inhibition in APP/PS1-21 mice but not in wild-type mice (Figure 5c). In all three brain regions, the percentage increase in $K_{\mathrm{p} \text {,brain }}$ of $\left[{ }^{11} \mathrm{C}\right]$ tariquidar following ABCG2 inhibition was not significantly different between APP/PS1-21 and wild-type mice (APP/PS1-21: 36-52\%, wild-type: 26-41\%).

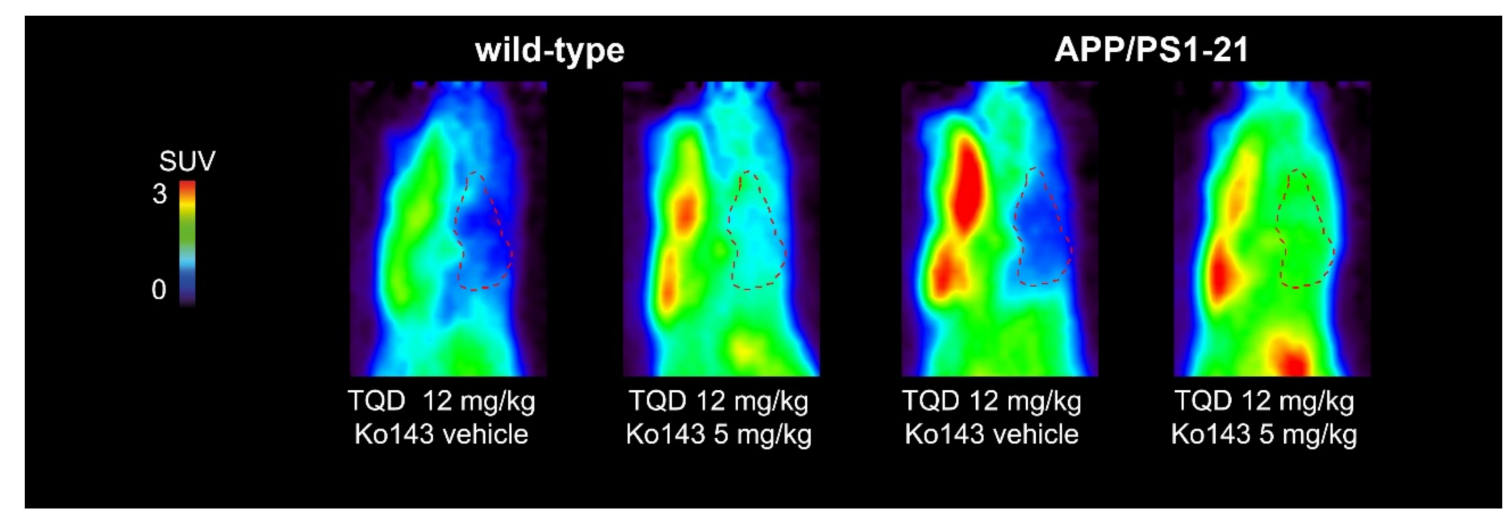

Figure 3. Sagittal (median axis) PET summation images (0-60 min) of 6-months-old APP/PS1-21 mice and age-matched wild-type mice pretreated i.v. with tariquidar (TQD, $12 \mathrm{mg} / \mathrm{kg}$ ) at $2 \mathrm{~h}$ and Ko143 vehicle solution or Ko143 $(5 \mathrm{mg} / \mathrm{kg})$ at $1 \mathrm{~h}$ prior to $\left[{ }^{11} \mathrm{C}\right]$ tariquidar PET. Whole brain region is outlined with a red broken line. All images are set to the same intensity scale ( $0-3$ standardized uptake value, SUV). 


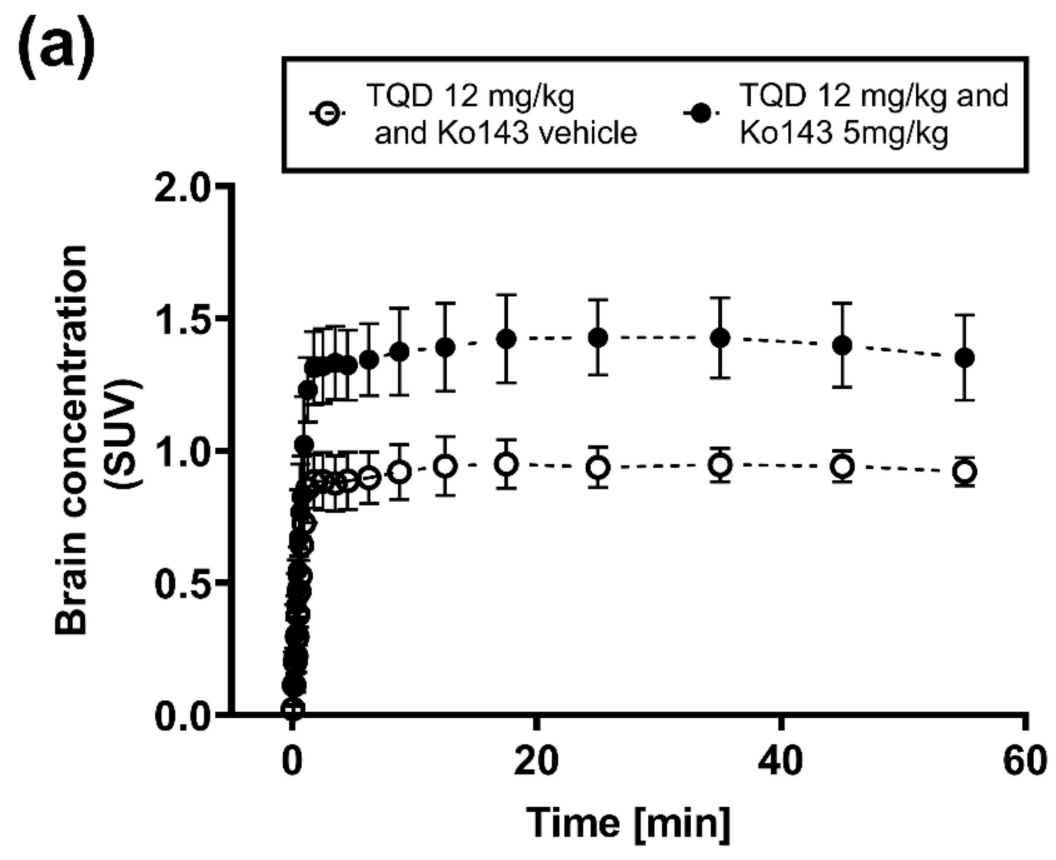

(b)

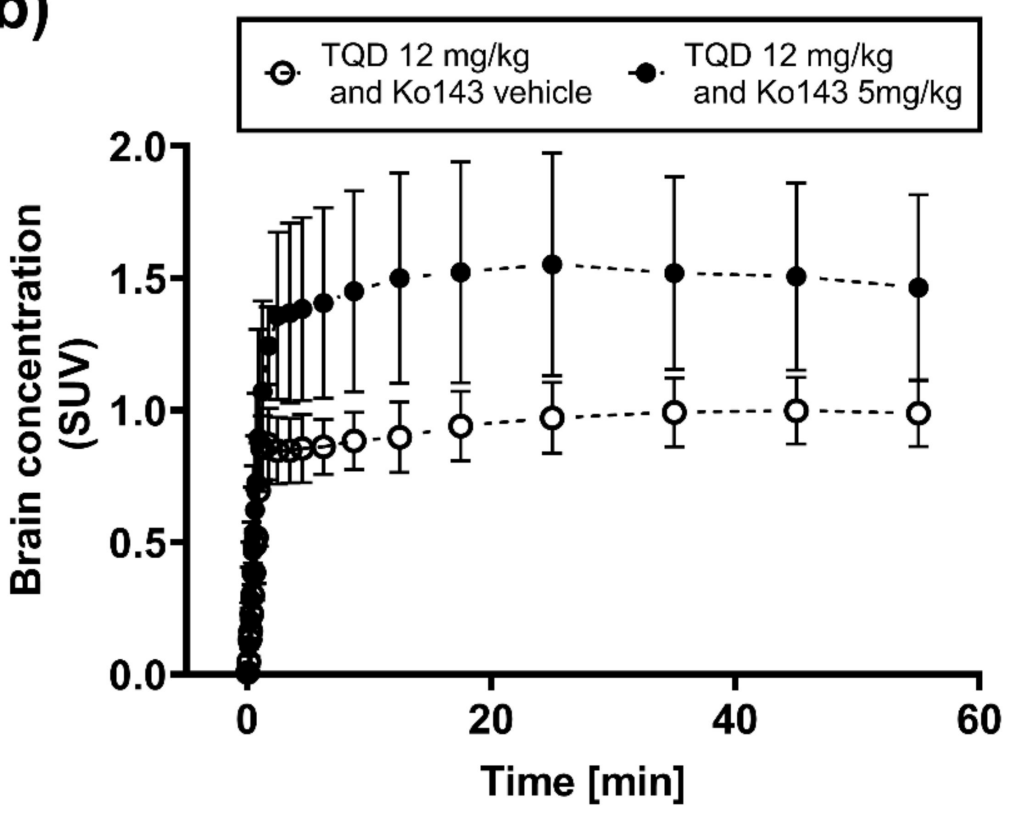

Figure 4. Time-activity curves (mean $\pm \mathrm{SD}$ ) of $\left[{ }^{11} \mathrm{C}\right]$ tariquidar in whole brains of (a) wild-type mice and (b) APP/PS1-21 mice pretreated with unlabeled tariquidar (TQD, $12 \mathrm{mg} / \mathrm{kg}$ ) at $2 \mathrm{~h}$ and Ko143 vehicle solution (open circles, wild-type: $n=6$, APP/PS1-21: $n=5$ ) or Ko143 (5 mg/kg, closed circles, wild-type: $n=7$, APP/PS1-21: $n=7$ ) at $1 \mathrm{~h}$ prior to PET acquisition. 
(a)

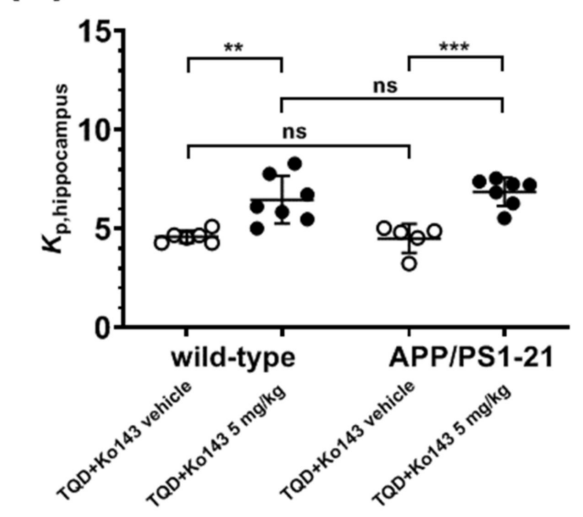

(b)

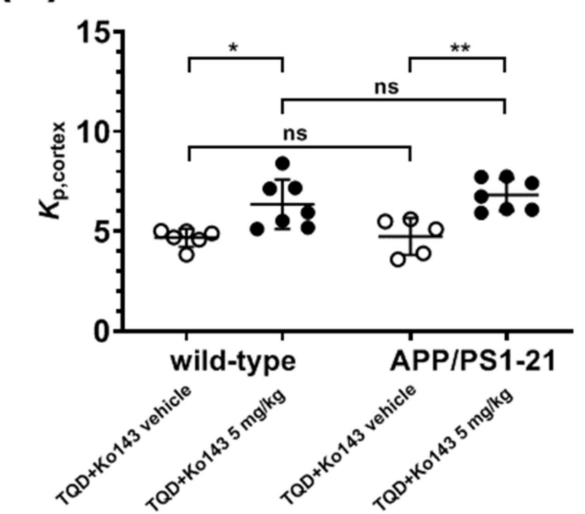

(c)

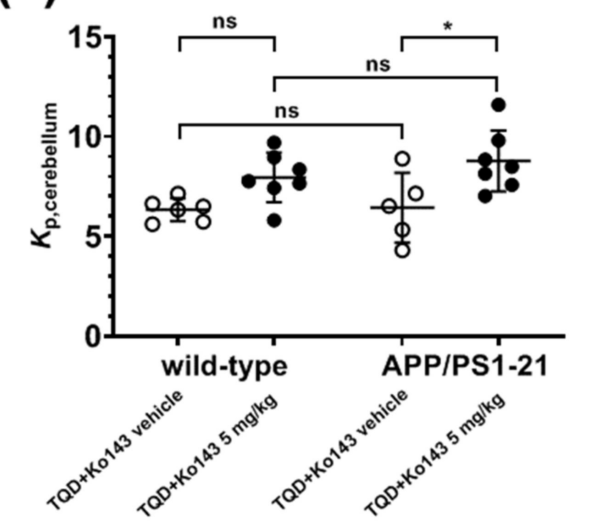

Figure 5. Regional brain-to-plasma radioactivity concentration ratios $\left(K_{\mathrm{p}, \text { brain }}\right)$ in (a) hippocampus, (b) cortex and (c) cerebellum at the end of the [ $\left.{ }^{11} \mathrm{C}\right]$ tariquidar PET scan in 6-months-old APP/PS1-21 mice and age-matched wild-type mice pretreated with unlabeled tariquidar (TQD, $12 \mathrm{mg} / \mathrm{kg}$ ) at $2 \mathrm{~h}$ and Ko143 vehicle solution (wild-type: $n=6$, APP/PS1-21: $n=5$ ) or Ko143 (5 mg/kg, wild-type: $n=7$, APP/PS1-21: $n=7$ ) at $1 \mathrm{~h}$ prior to the start of the PET scan. (ns, not significant; ${ }^{*} p<0.05$; ** $p<0.01$; ${ }^{* *} p<0.001$; compared to Ko143 vehicle treated animals; one-way ANOVA followed by Tukey's multiple comparison test).

\section{3. $\left[{ }^{11}\right.$ C]Erlotinib PET}

To confirm the lack of an effect of the decreased abundance of ABCG2 on the brain distribution of $\left[{ }^{11} \mathrm{C}\right]$ tariquidar, we performed PET scans with a second ABCB1/ABCG2 substrate radiotracer $\left(\left[{ }^{11} \mathrm{C}\right]\right.$ erlotinib) [35]. In contrast to $\left[{ }^{11} \mathrm{C}\right]$ tariquidar, $\mathrm{PET}$ scans were only performed under conditions of full ABCB1/ABCG2 activity, i.e., no ABCB1 or ABCG2 inhibitors were administered. To mimic the 
therapeutic usage of erlotinib, we co-injected $\left[{ }^{11} \mathrm{C}\right]$ erlotinib with a pharmacological dose of unlabeled erlotinib (2 mg/kg) [36]. Whole brain TACs of $\left[{ }^{11} \mathrm{C}\right]$ erlotinib were very similar in the two mouse strains (Figure $6 \mathrm{a}$ ). Moreover, $K_{\mathrm{p}, \text { brain }}$ values were not significantly different between APP/PS1-21 and wild-type mice in the three examined brain regions (hippocampus, cortex and cerebellum) (Figure 6b-d).

(a)

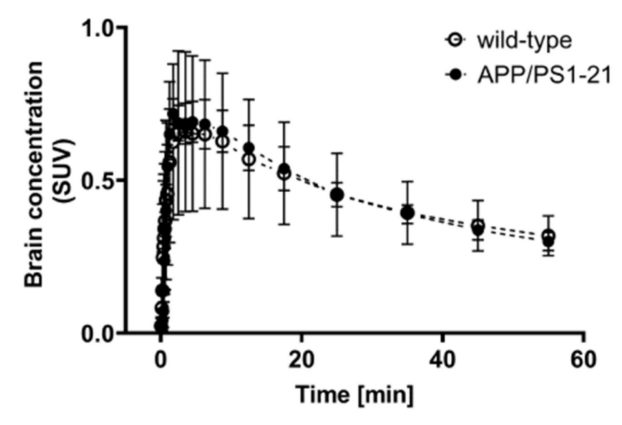

(c)

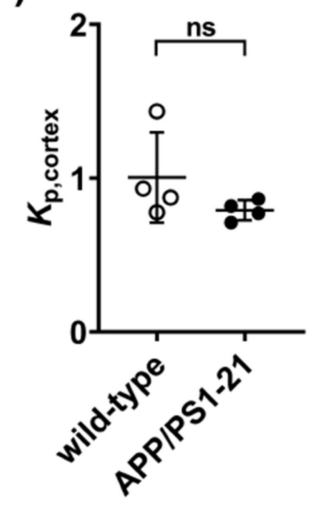

(b)

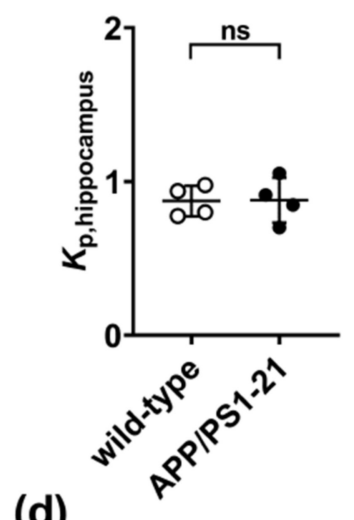

(d)

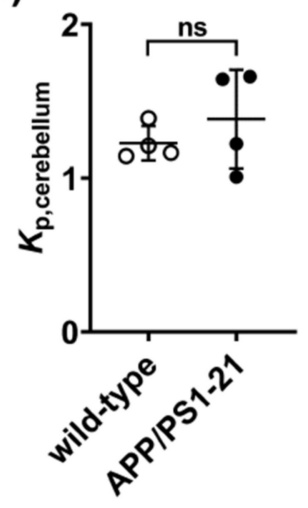

Figure 6. Time-activity curves (mean $\pm \mathrm{SD}$ ) of $\left[{ }^{11} \mathrm{C}\right]$ erlotinib in whole brains of 6 -months-old APP/PS1-21 mice (closed circles, $n=4)$ and age-matched wild-type mice (open circles, $n=4)(\mathbf{a})$. Regional brain-to-plasma radioactivity concentration ratios $\left(K_{\text {p,brain }}\right)$ in $(\mathbf{b})$ hippocampus, (c) cortex and (d) cerebellum at the end of the $\left[{ }^{11} \mathrm{C}\right]$ erlotinib PET scan in APP/PS1-21 mice and wild-type mice (ns, not significant; 2-sided $t$-test).

\section{Discussion}

ABCG2 was shown to be co-localized with $\mathrm{ABCB} 1$ at the $\mathrm{BBB}$, where both transporters limit the brain distribution of many therapeutic drugs [19,37]. Studies in transgenic mice have provided evidence for functional redundancy between ABCB1 and ABCG2 at the BBB [19,37]. In the absence of $A B C B 1$, the transport capacity of ABCG2 usually suffices to restrict the brain distribution of dual $A B C B 1 / A B C G 2$ substrates and vice versa. Only when both transporters are genetically knocked out or pharmacologically inhibited, do dual ABCB1/ABCG2 substrates show unrestricted brain distribution. Both $A B C B 1$ and $A B C G 2$ have been identified as $A \beta$ transporters $[5-9,22-24]$ and the abundance and activity of cerebral ABCB1 were found to be decreased in AD [10-14], which may be caused by an $A \beta$-induced ubiquitination, internalization and proteasomal degradation of $A B C B 1$ [38]. It is tempting to speculate that a similar functional redundancy between $A B C B 1$ and ABCG2 exists with respect to $A \beta$ export as described for restricting the brain distribution of small-molecule drugs [19,37]. Xiong et al. have shown an upregulation of ABCG2 in the brains of AD patients and AD mouse models (3XTg and Tg-SwDI) by means of immunohistochemistry and Western blot [22]. Moreover, these authors used optical imaging to show that the brain concentration of fluorescent-labeled $A \beta$ after i.v. injection was 
higher in $\mathrm{Abcg} 2^{(-/-)}$mice as compared with wild-type mice, which confirmed $\mathrm{A} \beta$ transport by mouse ABCG2 [22]. Other studies, however, were not able to confirm an ABCG2 upregulation in AD brains by using either immunohistochemistry [10-12] or quantitative targeted proteomics [25,26].

To further address these questions, in the present study we examined both the abundance and activity of cerebral ABCG2 in a commonly employed $\beta$-amyloidosis mouse model (APP/PS1-21) [32]. This mouse model rapidly develops extensive cerebral $A \beta$ deposits from an age of 2 months onwards [32,33] and has been used in a series of previous studies conducted in our laboratory to assess the activity of $A B C$ transporters implicated in brain $A \beta$ clearance with PET $[15,33,39]$. In a previous study we used immunohistochemical staining to show that the abundance of ABCB1 is decreased in the brains of APP/PS1-21 mice (i.e., in the hippocampus and the cortex) relative to wild-type mice of the same age range [33]. In the present study, using a comparable methodology we found a reduction in the number of ABCG2-stained microvessels in APP/PS1-21 mice (Figures 1 and 2). This reduction was not only found in the hippocampus, a brain region with high $A \beta$ load, but also in the cerebellum, in which $A \beta$ load is negligible [33]. Our analysis was not able to differentiate whether the reduced abundance of ABCG2 in the brains of APP/PS1-21 mice was caused by a decrease in vascular density [40] or by a decrease in the density of the transporter [11]. Therefore, additional experiments with a different methodology (e.g., Western blot analysis of isolated brain microvessels) will be needed to further examine the regional differences in ABCG2 observed in the present study.

To assess the consequences of these parallel reductions in the abundance of both ABCB1 and ABCG2, utilizing PET imaging, we studied the brain distribution of two radiotracers that are dual $\mathrm{ABCB} 1 / \mathrm{ABCG} 2$ substrates $\left(\left[{ }^{11} \mathrm{C}\right]\right.$ tariquidar and $\left[{ }^{11} \mathrm{C}\right]$ erlotinib $)$. As a first approach, we used a previously developed PET protocol dedicated to measuring cerebral ABCG2 activity [28-30]. This protocol uses the dual $\mathrm{ABCB} 1 / \mathrm{ABCG} 2$ substrate $\left[{ }^{11} \mathrm{C}\right]$ tariquidar [31] co-administered with a pharmacological dose of unlabeled tariquidar $(12 \mathrm{mg} / \mathrm{kg})$, which leads to complete saturation of ABCB1 activity while ABCG2 remains fully active, thereby ABCG2 selectivity is achieved. The attainment of ABCG2 selectivity is enabled by the great difference in half-maximum inhibitory concentrations $\left(\mathrm{IC}_{50}\right)$ of tariquidar for in vitro inhibition of its own transport by $\mathrm{ABCB} 1\left(\mathrm{IC}_{50}=17.1 \mathrm{nM}\right)$ and $\mathrm{ABCG} 2$ $\left(\mathrm{IC}_{50}=310.4 \mathrm{nM}\right)$ [30]. To reveal the activity of ABCG2, $\left[{ }^{11} \mathrm{C}\right]$ tariquidar PET scans were performed without and with pretreatment with the ABCG2 inhibitor Ko143 [34] at a dose that only partially inhibits ABCG2. The employed dose of Ko143 $(5 \mathrm{mg} / \mathrm{kg}$ ) was selected based on a previous dose-response curve generated in $A b c b 1 a / b^{(-/-)}$mice, which provided a half-maximum effect dose of Ko143 of $4.98 \mathrm{mg}$ to enhance brain uptake of $\left[{ }^{11} \mathrm{C}\right]$ tariquidar [28]. We determined $K_{\mathrm{p}, \text { brain }}$ as the outcome parameter of the brain distribution of $\left[{ }^{11} \mathrm{C}\right]$ tariquidar, which was in a similar range in both APP/PS1-21 and wild-type mice after $5 \mathrm{mg} / \mathrm{kg}$ Ko143 ( $K_{\mathrm{p} \text {,brain }}$ range: 6-8, see Figure 5) as in $A b c b 1 a / b^{(-)}$mice pretreated with $5 \mathrm{mg} / \mathrm{kg}$ Ko143 [28]. Maximum brain uptake of $\left[{ }^{11} \mathrm{C}\right]$ tariquidar amounted to a $K_{\mathrm{p} \text {,brain }}$ of approximately $15 \mathrm{in} A b c b 1 a / b^{(--)}$mice pretreated with $15 \mathrm{mg} / \mathrm{kg}$ Ko143, which was comparable to the brain uptake of $\left[{ }^{11} \mathrm{C}\right]$ tariquidar in $A b c b 1 a / b^{(-/)} A b c g 2^{(-/)}$mice [28]. Taken together, the present data as well as the previous Ko143 dose-response data strongly suggest that the dose of Ko143 employed in our study ( $5 \mathrm{mg} / \mathrm{kg}$ ) led to only partial ABCG2 inhibition at the mouse BBB. The experimental paradigm of studying transporter activity with a radiolabeled substrate by employing an inhibitor administered at a dose that only partially inhibits the transporter has been successfully employed by our group and by others to measure the activity of ABCB1 in the rodent and human brain with the ABCB1 substrate $(R)-\left[{ }^{11} C\right]$ verapamil $[33,41-44]$. For instance, only PET scans after partial inhibition of ABCB1 revealed significant differences in the brain distribution of $(R)-\left[{ }^{11} C\right]$ verapamil in APP/PS1-21 versus wild-type mice, while no differences were observed in baseline scans without ABCB1 inhibition [33]. In contrast to this previous study, we failed to detect differences in $\left[{ }^{11} \mathrm{C}\right]$ tariquidar brain distribution between APP/PS1-21 and wild-type mice, both under conditions of full ABCG2 activity and partial ABCG2 inhibition (Figure 5).

To confirm this apparent lack of difference in ABCG2 activity between APP/PS1-21 and wild-type mice, we also performed PET imaging in APP/PS1-21 and wild-type mice with a second dual 
ABCB1/ABCG2 substrate radiotracer. For this we used $\left[{ }^{11} \mathrm{C}\right]$ erlotinib, which is structurally identical to the epidermal growth factor receptor (EGFR)-targeting tyrosine kinase inhibitor erlotinib, a clinically used drug for the treatment of non-small cell lung cancer. Patients with this type of cancer often develop brain metastases, which are difficult to treat with erlotinib, most likely due to its low brain distribution caused by ABCB1/ABCG2-efflux transport at the BBB. We have previously shown that $\left[{ }^{11} \mathrm{C}\right]$ erlotinib is transported by mouse $\mathrm{ABCB} 1$ and $\mathrm{ABCG} 2$ and can be used to assess the functional redundancy between $\mathrm{ABCB} 1$ and $\mathrm{ABCG} 2$ at the mouse BBB [35]. To mimic the clinical use of this drug we co-injected $\left[{ }^{11} \mathrm{C}\right]$ erlotinib with a pharmacological dose of unlabeled erlotinib $(2 \mathrm{mg} / \mathrm{kg})$ [36]. Similar to the results obtained with $\left[{ }^{11} \mathrm{C}\right]$ tariquidar, we found no differences in the brain distribution of $\left[{ }^{11} \mathrm{C}\right]$ erlotinib between APP/PS1-21 and wild-type mice (Figure 6).

Our results are in line with and extend previous studies that failed to detect differences in the brain distribution of different drugs (including several ABCB1 substrates) between different $\beta$-amyloidosis mouse models and wild-type mice [15,45-47]. For instance, Gustafsson et al. found no differences in the unbound brain-plasma concentration ratios $\left(K_{\mathrm{p}, \mathrm{uu}, \mathrm{brain}}\right)$ of the ABCB1 substrates paliperidone and digoxin between tg-APP ${ }_{\text {ArcSwe }}$ and age-matched control mice [46]. Similarly, Mehta et al. found no changes in the brain distribution of the $\mathrm{ABCB} 1$ substrates loperamide, verapamil and digoxin in triple transgenic $\mathrm{AD}$ mice harboring three mutant genes $\left(A P P_{S w e}, P S-1_{M 146 V}\right.$ and $\left.t_{a u_{P 301 L}}\right)$, despite a reduction in the abundance of $A B C B 1$ in this mouse model as shown by Western blot analysis of isolated cerebral microvessels [45]. This was explained by Mehta et al. by a thickening of the basement membrane of the BBB in AD mice, which may have impeded transcellular diffusion and thereby counteracted the reduction in the abundance of $A B C B 1$. An alternative explanation for these previous findings may be that the changes in $\mathrm{ABCB} 1$ abundance in the $\mathrm{AD}$ mouse models were too low to cause significant changes in the brain distribution of $\mathrm{ABCB} 1$ substrates. $\mathrm{ABCB} 1$ is a high-capacity transporter, whose abundance needs to be reduced by $>50 \%$ to see $>2$-fold changes in the brain distribution of its substrates [48]. In line with this hypothesis, we have shown that the brain distribution of the ABCB1 substrate radiotracers $\left[{ }^{11} \mathrm{C}\right] N$-desmethyl-loperamide and $(R)-\left[{ }^{11} \mathrm{C}\right]$ verapamil was increased by only 1.1- and 1.5-fold, respectively, in heterozygous $A b c b 1 a / b$ knockout mice $\left(A b c b 1 a / b^{(+-)}\right)$, which have a $50 \%$ reduction in the abundance of $\mathrm{ABCB} 1$ at the $\mathrm{BBB}$, as compared with wild-type mice [49]. In contrast, in homozygous $A b c b 1 a / b$ knockout mice $\left(A b c b 1 a / b^{(-)}\right)$, which completely lack ABCB1, the brain distribution of $\left[{ }^{11} \mathrm{C}\right] N$-desmethyl-loperamide and $(R)-\left[{ }^{11} \mathrm{C}\right]$ verapamil was increased by 2.8 and 3.9- fold, respectively, relative to wild-type mice [49]. In our present study, we extended previous findings related to ABCB1 substrates $[15,45-47]$ to dual ABCB1/ABCG2 substrates and showed that despite a concomitant reduction in the abundance of cerebral ABCB1 and ABCG2 in APP/PS1-21 mice as revealed by immunohistochemistry, the brain distribution of the dual ABCB1/ABCG2 substrates $\left[{ }^{11} \mathrm{C}\right]$ tariquidar and $\left[{ }^{11} \mathrm{C}\right]$ erlotinib was unaltered. While caution is warranted in extrapolating these results to humans, our results suggest that the brain distribution of clinically used ABCB1/ABCG2 substrate drugs may be unaffected by possible disease-induced alterations in transporter abundances at the $\mathrm{BBB}$ of $\mathrm{AD}$ patients.

Limitations of our study include the low number of animals used for immunohistochemical analysis, our inability to differentiate between a reduction in vascular density and a reduction in the density of ABCG2, and the lack of further experimental data to confirm the reduction in cerebral ABCG2 (e.g., Western blot analysis of ABCG2 in isolated brain microvessels).

\section{Materials and Methods}

\subsection{General}

Unless otherwise stated, all chemicals were purchased from Sigma-Aldrich Chemie (Schnelldorf, Germany) or Merck (Darmstadt, Germany) and were of analytical grade and used without further purification. The ABCB1 inhibitor tariquidar dimesylate [50] was obtained from Haoyuan Chemexpress Co. Ltd. (Shanghai, China). The ABCG2 inhibitor Ko143 [34] was purchased from Enzo Life Sciences 
AG (Lausen, Switzerland) or MedChemExpress LLC (Monmouth Junction, NJ, USA). Isoflurane was obtained from VIRBAC S.A. (Carros, France). Directly prior to administration, tariquidar dimesylate was freshly dissolved in $2.5 \%(w / v)$ aqueous (aq.) dextrose solution and injected intravenously (i.v.) into mice at a volume of $4 \mathrm{~mL} / \mathrm{kg}$ body weight over a period of $2 \mathrm{~min}$. Ko143 was freshly dissolved in ethanol and formulated for i.v. administration in a solution containing 10\% $(v / v)$ Kolliphor HS 15 and $80 \%(v / v)$ sterile aqueous saline to a final ethanol concentration of $10 \%(v / v)$. Formulated Ko143 solution was injected into mice at a volume of $2 \mathrm{~mL} / \mathrm{kg}$ body weight over a period of 3-5 min.

\subsection{Radiotracer Synthesis and Formulation}

$\left[{ }^{11} \mathrm{C}\right]$ Tariquidar was synthesized as described previously [51]. For i.v. injection, $\left[{ }^{11} \mathrm{C}\right]$ tariquidar was formulated in sterile aqueous saline containing $0.01 \%(w / v)$ Tween 80 to an approximate concentration of $370 \mathrm{MBq} / \mathrm{mL}$. Radiochemical purity, as determined by radio-high performance liquid chromatography, was greater than $98 \%$, and molar activity at the end of synthesis was $>100 \mathrm{GBq} / \mu \mathrm{mol}$.

$\left[{ }^{11} \mathrm{C}\right]$ Erlotinib was synthesized following established procedures [52] with a radiochemical purity of $>98 \%$ and a molar activity of $>100 \mathrm{GBq} / \mu \mathrm{mol}$ at end of synthesis. For administration into mice, $\left[{ }^{11} \mathrm{C}\right]$ erlotinb was formulated in $0.1 \mathrm{mM}$ hydrochloric acid in sterile aqueous saline solution to yield a concentration of approximately $370 \mathrm{MBq} / \mathrm{mL}$.

\subsection{Animals}

Female transgenic mice, which express mutated human amyloid precursor protein (APP) and presenilin 1 (PS1) under control of the Thy1-promoter $\left(\mathrm{APP}_{\mathrm{KM} 670 / 671 \mathrm{NL}}, \mathrm{PS}_{\mathrm{L} 166 \mathrm{P}}\right.$ ) (referred to as APP/PS1-21 mice) [32,33] and age-matched wild-type littermates in a C57BL/6J genetic background were maintained at the University of Oslo and transferred to the imaging site at least three weeks prior to the PET examinations. In total, 50 mice were used in the experiments. All animals were housed in groups of 3-5 animals in individually ventilated (IVC) type III cages under controlled environmental conditions ( $22 \pm 3{ }^{\circ} \mathrm{C}, 40 \%$ to $70 \%$ humidity, 12-h light/dark cycle) and had free access to standard laboratory animal diet (ssniff R/M-H, ssniff Spezialdiäten GmbH, Soest, Germany) and water ad libitum. The study was reviewed by the responsible national authorities (Amt der Niederösterreichischen Landesregierung) and approved under study numbers LF1-TVG-48/003-2014 approval date: 08 January 2015 and LF1-TVG-48/044-2019 approval date: 07 May 2019. All study procedures were in accordance with the European Community's Council Directive of September 22, 2010 (2010/63/EU). The animal experimental data reported in this study are in compliance with the ARRIVE (Animal Research: Reporting In Vivo Experiments) guidelines.

\subsection{Experimental Design and Pretreatment}

Female APP/PS1-21 and wild-type animals were assigned to the respective groups as shown in Table 1. Two PET imaging approaches for assessing the activity of ABCG2 at the mouse BBB were performed using the two $A B C B 1 / A B C G 2$ substrate radiotracers $\left[{ }^{11} \mathrm{C}\right]$ tariquidar $[28,31]$ and $\left[{ }^{11}\right.$ C]erlotinib [35]:

(1) For PET imaging using $\left[{ }^{11} \mathrm{C}\right]$ tariquidar, groups of APP/PS1-21 and wild-type mice aged $185 \pm 5$ days and weighing $27.2 \pm 3.0$ g were pretreated two hours prior to PET with unlabeled tariquidar administered i.v. at a dose of $12 \mathrm{mg} / \mathrm{kg}$ in awake condition. Subsequently, animals were anesthetized using isoflurane/air, a catheter (Instech Lab. Inc., Plymouth Meeting, PA, USA) was introduced into a lateral tail vein and Ko143 at a dose of $5 \mathrm{mg} / \mathrm{kg}$ or Ko143 vehicle solution was additionally administered to the animals i.v. one hour prior to the start of PET acquisition. Subsequently, mice underwent a 60-min dynamic $\left[{ }^{11} \mathrm{C}\right]$ tariquidar PET scan. The doses of tariquidar and Ko143 were selected based on previous work to achieve full inhibition of ABCB1 [49] and partial inhibition of ABCG2 [28] at the mouse BBB.

(2) For PET imaging using $\left[{ }^{11} \mathrm{C}\right]$ erlotinib, no pretreatment was applied. Groups of APP/PS1-21 and wild-type mice aged $177 \pm 2$ days and weighing $25.1 \pm 2.9 \mathrm{~g}$ were prepared for imaging following 
the procedures described below and underwent a 60-min dynamic $\left[{ }^{11} \mathrm{C}\right]$ erlotinib PET scan, in which a pharmacological dose of unlabeled erlotinib $(2 \mathrm{mg} / \mathrm{kg})$ was co-injected with [ ${ }^{11} \mathrm{C}$ ]erlotinib [36].

Table 1. Overview of examined animal groups and numbers.

\begin{tabular}{|c|c|c|c|}
\hline \multirow{2}{*}{$\begin{array}{c}\left.{ }^{[11} \mathrm{C}\right] \text { Tariquidar Study } \\
\text { Pretreatment }\end{array}$} & & \multicolumn{2}{|c|}{ Animal Group } \\
\hline & & Wild-Type & APP/PS1-21 \\
\hline \multirow[t]{4}{*}{$\begin{array}{l}\text { Tariquidar (12 mg/kg) } \\
\text { and Ko143 vehicle }\end{array}$} & $n$ & $10(4)^{1}$ & $7(2)$ \\
\hline & Age [days] ${ }^{2}$ & $189 \pm 4$ & $188 \pm 1$ \\
\hline & Body weight $[g]^{2}$ & $26.7 \pm 2.1$ & $27.9 \pm 3.2$ \\
\hline & Injected activity $[\mathrm{MBq}]^{3}$ & $28 \pm 6$ & $25 \pm 3$ \\
\hline \multirow{4}{*}{$\begin{array}{l}\text { Tariquidar (12 mg/kg) } \\
\text { and Ko143 (5 mg/kg) }\end{array}$} & $n$ & $11(4)$ & $12(5)$ \\
\hline & Age [days] & $181 \pm 5$ & $183 \pm 6$ \\
\hline & Body weight $[g]$ & $28.9 \pm 3.3$ & $25.3 \pm 2.4$ \\
\hline & Injected activity [MBq] & $24 \pm 7$ & $23 \pm 10$ \\
\hline \multirow[t]{6}{*}[{}^{11}\mathrm{C}]{ Erlotinib Study } & & \multicolumn{2}{|c|}{ Animal Group } \\
\hline & & Wild-Type & APP/PS1-21 \\
\hline & $n$ & $5(1)$ & $5(1)$ \\
\hline & Age [days] & $176 \pm 1$ & $179 \pm 2$ \\
\hline & Body weight $[\mathrm{g}]$ & $25.1 \pm 1.2$ & $25.2 \pm 4.3$ \\
\hline & Injected activity [MBq] & $19 \pm 3$ & $26 \pm 4$ \\
\hline
\end{tabular}

\footnotetext{
${ }^{1}$ Number in parentheses indicates drop-outs due to death/intolerability of the protocol; ${ }^{2}$ At date of PET examination;

${ }^{3}$ Injected amounts of radioactivity.
}

\subsection{PET Imaging Procedure}

For PET imaging, mice were pre-anesthetized in an induction chamber using isoflurane and then positioned in a prone position on a double imaging chamber ( $\mathrm{m} 2 \mathrm{~m}$ Imaging Corp, Cleveland, $\mathrm{OH}, \mathrm{USA})$. Two mice were imaged simultaneously during one PET acquisition. Animals were warmed throughout the experiment and body temperature and respiratory rate were constantly monitored (SA Instruments Inc, Stony Brook, NY, USA). The level of isoflurane concentration was adjusted (range 1.5-3\% in air) during the imaging procedure to achieve a constant level of anesthesia. The imaging chamber was positioned in the gantry of a microPET scanner (Focus 220, Siemens Medical Solutions, Knoxville, $\mathrm{TN}, \mathrm{USA}$ ) and a $10 \mathrm{~min}$ transmission scan using a rotating ${ }^{57} \mathrm{Co}$ point source was recorded. Subsequently, 60-min dynamic emission scans (energy window 250-750 keV; timing window $=6 \mathrm{~ns}$ ) were started with the injection of either $\left[{ }^{11} \mathrm{C}\right]$ tariquidar $(25 \pm 7 \mathrm{MBq})$ or $\left[{ }^{11} \mathrm{C}\right]$ erlotinib $(22 \pm 5 \mathrm{MBq})$ injected i.v. at a volume of $0.1 \mathrm{~mL}$ over a period of $120 \mathrm{~s}$.

After completion of the PET scan, a blood sample (20-30 $\mu \mathrm{L})$ was collected from the retro-orbital venous plexus, the mice were sacrificed by cervical dislocation and transcardially perfused using $10 \mathrm{~mL}$ phosphate-buffered saline. Blood was centrifuged $\left(13,000 \times g, 4{ }^{\circ} \mathrm{C}, 4 \mathrm{~min}\right)$ to obtain plasma and whole brains were removed and processed for immunohistochemistry as described below. Aliquots of blood and plasma were transferred into pre-weighted test tubes and measured in a gamma-counter (HIDEX AMG Automatic Gamma Counter, Turku, Finland). Filled tubes were weighed to obtain tissue weight. The gamma-counter was calibrated using a series of tubes with decreasing activity of a ${ }^{11} \mathrm{C}$-solution. The measured radioactivity data were decay-corrected to the time of radiotracer injection and expressed as standardized uptake value (SUV), which is calculated as follows: (radioactivity per g $(\mathrm{kBq} / \mathrm{g}) /$ injected radioactivity $(\mathrm{kBq})) \times$ body weight $(\mathrm{g})$.

\subsection{PET Data Analysis}

The dynamic PET data were binned into 23 frames, which increased incrementally in time length. PET images were reconstructed using Fourier re-binning of the 3-dimensional sinograms followed by a 
2-dimensional filtered back-projection with a ramp filter giving a voxel size of $(0.4 \times 0.4 \times 0.796) \mathrm{mm}^{3}$. Using Amide (version 1.0.4.) [53] or PMOD software (version 3.6, PMOD Technologies Ltd., Zurich, Switzerland) volumes of interest (VOI) covering the whole brain as well as the cortex, hippocampus and cerebellum region were outlined on the PET images with the aid of the Mirrione Mouse Atlas and guided by representative magnetic resonance (MR) images obtained in comparable animals on a 1 Tesla benchtop MR scanner (ICON, Bruker BioSpin GmbH, Ettlingen, Germany). From the VOIs, time-activity curves (TACs) were derived and expressed in SUV units. Whole brain and regional brain uptake was expressed as the brain-to-plasma radioactivity concentration ratio in the last PET frame $\left(K_{\mathrm{p}, \text { brain }}\right)$ [28]. For calculation of $K_{\mathrm{p}, \text { brain, }}$ the radioactivity concentration derived from the last PET time frame (from 50-60 min after injection) was divided by the radioactivity concentration measured with the gamma-counter in the plasma sample obtained after the PET scan.

\subsection{Immunohistochemistry}

Freshly harvested brains from animals that had undergone $\left[{ }^{11} \mathrm{C}\right]$ erlotinib PET scans were immediately washed with $30 \%$ aq. sucrose solution and embedded in freezing medium (Tissue-Tek, Sakura Finetek, Staufen, Germany). Samples were snap frozen in liquid nitrogen and stored at $-80{ }^{\circ} \mathrm{C}$ until further processed.

After defrosting from $-80{ }^{\circ} \mathrm{C}$ to $-20^{\circ} \mathrm{C}$ brains were cut in transversal orientation in $10 \mu \mathrm{m}$ thick slices using a cryostat (Microm HM 550, Walldorf, Germany). Frozen sections of three brain regions including the hippocampus, cortex, and cerebellum were mounted on coated slides (VWR Superfrost Plus) and stored at $-80^{\circ} \mathrm{C}$ until the staining procedure was initiated.

For immunohistochemical staining of mouse ABCG2, the thawed brain slices were fixed with methanol/acetone (1:1) for $10 \mathrm{~min}$ at $4{ }^{\circ} \mathrm{C}$. After washing with $0.1 \mathrm{M}$ tris-buffered saline solution (TBS), endogenous peroxidase activity was quenched by incubation with $0.5 \%(v / v)$ hydrogen peroxide in TBS for $30 \mathrm{~min}$. In order to obtain standardized staining results, the slides were washed and inserted into cover plates (Thermo Scientific ${ }^{\mathrm{TM}}$ Shandon ${ }^{\mathrm{TM}}$ Glass Coverplates, Fisher Scientific, Vienna, Austria). Blocking solution was added for $1 \mathrm{~h}$ at room temperature to suppress non-specific reactions. Anti-BCRP/ABCG2 antibody (1:400, [BXP-53, ab24115], Abcam) or antibody carrier solution (negative control) was used to incubate the brain slices overnight at $4{ }^{\circ} \mathrm{C}$. After washing the slides with TBS, slides were incubated with the secondary antibody (1:500, Biotin-SP (long spacer) AffiniPure Donkey Anti-Rat IgG (H + L), Jackson Immuno Research, West Grove, PA, USA) for $60 \mathrm{~min}$ at room temperature. Following three further washing steps, the antibody signals were amplified for $60 \mathrm{~min}$ at room temperature employing the VectaStain ABC-Kit (Vector Laboratories Inc, Burlingame, CA, USA). After rinsing, the slides were incubated in nickel/diaminobenzidine solution for $10 \mathrm{~min}$ to visualize ABCG2. The slides were then washed, dehydrated and mounted using Entellan ${ }^{\circledR}$ (Merck Darmstadt, Germany).

The mounted slides were scanned at $(0.11 \times 0.11) \mu \mathrm{m} /$ pixel resolution using a digital slide scanner (Pannoramic Desk, 3dHistech Ltd., Budapest, Hungary) and digital images of comparable regions in the hippocampus, cortex and cerebellum of APP/PS1-21 and wild-type mice were extracted. For the semi-quantitative evaluation of stained microvessels, four visual fields ( $20 \times$ digital magnification) in the same brain region per mouse ( $n=3$ animals per group) were counted manually on the digital images by the same operator. The operator was not blinded to the study groups. However, the digital images were selected randomly for manual counting to avoid bias. Due to high background staining automatic analysis was not possible.

\subsection{Statistical Analysis}

To analyze differences between two groups a 2-sided $t$-test and between multiple groups a one-way ANOVA followed by a Tukey's multiple comparison test were employed using Prism 8 software (GraphPad Software, La Jolla, CA, USA). The level of statistical significance was set to $p<0.05$. All values are given as mean \pm standard deviation (SD). 


\section{Conclusions}

Despite significant reductions in the abundance of the $A \beta$ transporters $A B C B 1$ and $A B C G 2$ in the brains of APP/PS1-21 mice, the brain distribution of the dual ABCB1/ABCG2 substrates $\left[{ }^{11} \mathrm{C}\right]$ tariquidar and $\left[{ }^{11} \mathrm{C}\right]$ erlotinib was unaltered relative to wild-type mice. This may be related to the high transport capacities of $A B C B 1$ and ABCG2 and is in line and extends previous studies, which failed to detect differences in the brain distribution of diverse $A B C B 1$ substrates between different $A D$ mouse models and wild-type mice. While caution is warranted in extrapolating our results to the human BBB, our findings suggest that while disease-induced alterations in the abundance of ABCB1 and ABCG2 may be sufficient to decrease the brain clearance of $A \beta$ peptides, they may not be sufficient to cause large changes in the brain distribution of clinically used ABCB1/ABCG2 substrate drugs.

Author Contributions: Conceptualization, T.W. and O.L.; methodology, T.W., S.M., M.K., M.B., T.P. and T.F.; PET investigation, T.F., M.S., V.Z., S.M. and J.S.; data analysis, V.Z. and T.W.; writing-original draft preparation, T.W. and O.L.; writing-review and editing, V.Z., T.F., T.P. and J.P.; visualization, V.Z. and T.W.; supervision, T.W. and O.L.; project administration, T.W.; funding acquisition, T.W., J.P. and O.L. All authors have read and agreed to the published version of the manuscript.

Funding: This research was funded by the Lower Austria Corporation for Research and Education (NFB) [grant number LS14-008, to T.W.], the Austrian Science Fund (FWF) [grant number I 1609-B24, to O. L.] and the Deutsche Forschungsgemeinschaft (DFG) [grant number DFG PA930/9, to J.P.]. The work of J.P. was also supported by the following grants: Deutsche Forschungsgemeinschaft/Germany (DFG PA930/12); Ministerium für Wirtschaft und Wissenschaft Sachsen-Anhalt/Germany (ZS/2016/05/78617); Leibniz Gemeinschaft/Germany (SAW-2015-IPB-2); Latvian Council of Science/Latvia (lzp-2018/1-0275); Nasjonalforeningen (16154), HelseSØ/Norway (2016062, 2019054, 2019055); Barnekreftforeningen (19008); Norges forskningsrådet/Norway (251290, 260786 (PROP-AD), 295910). PROP-AD is an EU Joint Programme-Neurodegenerative Disease Research (JPND) project and has received funding from the European Union's Horizon 2020 research and innovation programme under grant agreement \#643417 (JPco-fuND).

Acknowledgments: The authors wish to thank Mathilde Löbsch for help in conducting the PET experiments and Alina Zwickl, Jaqueline Koller, Marlies Nemeth and Monika Kühteubl (University of Applied Sciences, Wiener Neustadt, Austria) for support with immunohistochemistry. Open Access Funding by the Austrian Science Fund (FWF).

Conflicts of Interest: The authors declare no conflict of interest.

\section{Abbreviations}

ABC Adenosine triphopshate-binding cassette

ABCB1 ABC subfamily B member 1, also known as P-glycoprotein (P-gp)

ABCG2 ABC subfamily G member 2, also known as breast cancer resistance protein (BCRP)

$\mathrm{AD} \quad$ Alzheimer's disease

$\mathrm{A} \beta \quad$ Beta-amyloid

BBB Blood-brain barrier

$K_{\mathrm{p} \text {,brain }} \quad$ Brain-to-plasma radioactivity concentration ratio

PET Positron Emission Tomography

SUV Standardized uptake value

TAC Time-activity curve

\section{References}

1. Mawuenyega, K.G.; Sigurdson, W.; Ovod, V.; Munsell, L.; Kasten, T.; Morris, J.C.; Yarasheski, K.E.; Bateman, R.J. Decreased clearance of CNS beta-amyloid in Alzheimer's disease. Science 2010, 330, 1774. [CrossRef]

2. Hardy, J.; Allsop, D. Amyloid deposition as the central event in the aetiology of Alzheimer's disease. Trends Pharmacol. Sci. 1991, 12, 383-388.

3. Pahnke, J.; Wolkenhauer, O.; Krohn, M.; Walker, L.C. Clinico-pathologic function of cerebral ABC transporters-implications for the pathogenesis of Alzheimer's disease. Curr. Alzheimer Res. 2008, $5,396-405$. 
4. Boland, B.; Yu, W.H.; Corti, O.; Mollereau, B.; Henriques, A.; Bezard, E.; Pastores, G.M.; Rubinsztein, D.C.; Nixon, R.A.; Duchen, M.R.; et al. Promoting the clearance of neurotoxic proteins in neurodegenerative disorders of ageing. Nat. Rev. Drug Discov. 2018, 17, 660-688.

5. Storck, S.E.; Hartz, A.M.S.; Bernard, J.; Wolf, A.; Kachlmeier, A.; Mahringer, A.; Weggen, S.; Pahnke, J.; Pietrzik, C.U. The concerted amyloid-beta clearance of LRP1 and ABCB1/P-gp across the blood-brain barrier is linked by PICALM. Brain. Behav. Immun. 2018, 73, 21-33.

6. Lam, F.C.; Liu, R.; Lu, P.; Shapiro, A.B.; Renoir, J.M.; Sharom, F.J.; Reiner, P.B. beta-Amyloid efflux mediated by p-glycoprotein. J. Neurochem. 2001, 76, 1121-1128.

7. Kuhnke, D.; Jedlitschky, G.; Grube, M.; Krohn, M.; Jucker, M.; Mosyagin, I.; Cascorbi, I.; Walker, L.C.; Kroemer, H.K.; Warzok, R.W.; et al. MDR1-P-glycoprotein (ABCB1) mediates transport of Alzheimer's amyloid-beta peptides-implications for the mechanisms of Abeta clearance at the blood-brain barrier. Brain Pathol. 2007, 17, 347-353.

8. Hartz, A.M.; Miller, D.S.; Bauer, B. Restoring blood-brain barrier P-glycoprotein reduces brain amyloid-beta in a mouse model of Alzheimer's disease. Mol. Pharmacol. 2010, 77, 715-723.

9. Cirrito, J.R.; Deane, R.; Fagan, A.M.; Spinner, M.L.; Parsadanian, M.; Finn, M.B.; Jiang, H.; Prior, J.L.; Sagare, A.; Bales, K.R.; et al. P-glycoprotein deficiency at the blood-brain barrier increases amyloid-beta deposition in an Alzheimer disease mouse model. J. Clin. Investig. 2005, 115, 3285-3290.

10. Wijesuriya, H.C.; Bullock, J.Y.; Faull, R.L.; Hladky, S.B.; Barrand, M.A. ABC efflux transporters in brain vasculature of Alzheimer's subjects. Brain Res. 2010, 1358, 228-238.

11. Kannan, P.; Schain, M.; Kretzschmar, W.W.; Weidner, L.; Mitsios, N.; Gulyas, B.; Blom, H.; Gottesman, M.M.; Innis, R.B.; Hall, M.D.; et al. An automated method measures variability in P-glycoprotein and ABCG2 densities across brain regions and brain matter. J. Cereb. Blood Flow Metab. 2017, 37, 2062-2075.

12. Carrano, A.; Snkhchyan, H.; Kooij, G.; van der Pol, S.; van Horssen, J.; Veerhuis, R.; Hoozemans, J.; Rozemuller, A.; de Vries, H.E. ATP-binding cassette transporters P-glycoprotein and breast cancer related protein are reduced in capillary cerebral amyloid angiopathy. Neurobiol. Aging 2014, 35, 565-575.

13. van Assema, D.M.; Lubberink, M.; Bauer, M.; van der Flier, W.M.; Schuit, R.C.; Windhorst, A.D.; Comans, E.F.; Hoetjes, N.J.; Tolboom, N.; Langer, O.; et al. Blood-brain barrier P-glycoprotein function in Alzheimer's disease. Brain 2012, 135 (Pt 1), 181-189.

14. Deo, A.K.; Borson, S.; Link, J.M.; Domino, K.; Eary, J.F.; Ke, B.; Richards, T.L.; Mankoff, D.A.; Minoshima, S.; O'Sullivan, F; et al. Activity of P-glycoprotein, a beta-amyloid transporter at the blood-brain barrier, is compromised in patients with mild Alzheimer disease. J. Nucl. Med. 2014, 55, 1106-1111.

15. Zoufal, V.; Mairinger, S.; Brackhan, M.; Krohn, M.; Filip, T.; Sauberer, M.; Stanek, J.; Wanek, T.; Tournier, N.; Bauer, M.; et al. Imaging P-glycoprotein induction at the blood-brain barrier of a beta-amyloidosis mouse model with ${ }^{11}$ C-metoclopramide PET. J. Nucl. Med. 2020, 61, 1050-1057.

16. Qosa, H.; Abuznait, A.H.; Hill, R.A.; Kaddoumi, A. Enhanced brain amyloid-beta clearance by rifampicin and caffeine as a possible protective mechanism against Alzheimer's disease. J. Alzheimers Dis. 2012, 31, 151-165.

17. Durk, M.R.; Han, K.; Chow, E.C.; Ahrens, R.; Henderson, J.T.; Fraser, P.E.; Pang, K.S. 1alpha,25-Dihydroxyvitamin D3 reduces cerebral amyloid-beta accumulation and improves cognition in mouse models of Alzheimer's disease. J. Neurosci. 2014, 34, 7091-7101.

18. Brenn, A.; Grube, M.; Jedlitschky, G.; Fischer, A.; Strohmeier, B.; Eiden, M.; Keller, M.; Groschup, M.H.; Vogelgesang, S. St. John's Wort reduces beta-amyloid accumulation in a double transgenic Alzheimer's disease mouse model-role of P-glycoprotein. Brain Pathol. 2014, 24, 18-24.

19. Agarwal, S.; Hartz, A.M.; Elmquist, W.F.; Bauer, B. Breast cancer resistance protein and P-glycoprotein in brain cancer: Two gatekeepers team up. Curr. Pharm. Des. 2011, 17, 2793-2802.

20. Durmus, S.; Hendrikx, J.J.; Schinkel, A.H. Apical ABC transporters and cancer chemotherapeutic drug disposition. Adv. Cancer Res. 2015, 125, 1-41.

21. Vogelgesang, S.; Warzok, R.W.; Cascorbi, I.; Kunert-Keil, C.; Schroeder, E.; Kroemer, H.K.; Siegmund, W.; Walker, L.C.; Pahnke, J. The role of P-glycoprotein in cerebral amyloid angiopathy; implications for the early pathogenesis of Alzheimer's disease. Curr. Alzheimer Res. 2004, 1, 121-125.

22. Xiong, H.; Callaghan, D.; Jones, A.; Bai, J.; Rasquinha, I.; Smith, C.; Pei, K.; Walker, D.; Lue, L.F.; Stanimirovic, D.; et al. ABCG2 is upregulated in Alzheimer's brain with cerebral amyloid angiopathy and may act as a gatekeeper at the blood-brain barrier for Abeta(1-40) peptides. J. Neurosci. 2009, 29, 5463-5475. 
23. Tai, L.M.; Loughlin, A.J.; Male, D.K.; Romero, I.A. P-glycoprotein and breast cancer resistance protein restrict apical-to-basolateral permeability of human brain endothelium to amyloid-beta. J. Cereb. Blood Flow Metab. 2009, 29, 1079-1083.

24. Do, T.M.; Noel-Hudson, M.S.; Ribes, S.; Besengez, C.; Smirnova, M.; Cisternino, S.; Buyse, M.; Calon, F.; Chimini, G.; Chacun, H.; et al. ABCG2- and ABCG4-mediated efflux of amyloid-beta peptide 1-40 at the mouse blood-brain barrier. J. Alzheimers Dis. 2012, 30, 155-166.

25. Storelli, F.; Billington, S.; Kumar, A.R.; Unadkat, J.D. Abundance of P-glycoprotein and other drug transporters at the human blood-brain barrier in Alzheimer's Disease: A quantitative targeted proteomic study. Clin. Pharmacol. Ther. 2020. [CrossRef]

26. Al-Majdoub, Z.M.; Al Feteisi, H.; Achour, B.; Warwood, S.; Neuhoff, S.; Rostami-Hodjegan, A.; Barber, J. Proteomic quantification of human blood-brain barrier SLC and ABC transporters in healthy individuals and dementia patients. Mol. Pharm. 2019, 16, 1220-1233.

27. Wanek, T.; Mairinger, S.; Langer, O. Radioligands targeting P-glycoprotein and other drug efflux proteins at the blood-brain barrier. J. Labelled Comp. Radiopharm. 2013, 56, 68-77.

28. Wanek, T.; Kuntner, C.; Bankstahl, J.P.; Mairinger, S.; Bankstahl, M.; Stanek, J.; Sauberer, M.; Filip, T.; Erker, T.; Müller, M.; et al. A novel PET protocol for visualization of breast cancer resistance protein function at the blood-brain barrier. J. Cereb. Blood Flow Metab. 2012, 32, 2002-2011.

29. Dallas, S.; Salphati, L.; Gomez-Zepeda, D.; Wanek, T.; Chen, L.; Chu, X.; Kunta, J.; Mezler, M.; Menet, M.C.; Chasseigneaux, S.; et al. Generation and characterization of a breast cancer resistance protein humanized mouse model. Mol. Pharmacol. 2016, 89, 492-504.

30. Bauer, M.; Römermann, K.; Karch, R.; Wulkersdorfer, B.; Stanek, J.; Philippe, C.; Maier-Salamon, A.; Haslacher, H.; Jungbauer, C.; Wadsak, W.; et al. Pilot PET study to assess the functional interplay between ABCB1 and ABCG2 at the human blood-brain barrier. Clin. Pharmacol. Ther. 2016, 100, 131-141.

31. Bankstahl, J.P.; Bankstahl, M.; Römermann, K.; Wanek, T.; Stanek, J.; Windhorst, A.D.; Fedrowitz, M.; Erker, T.; Müller, M.; Löscher, W.; et al. Tariquidar and elacridar are dose-dependently transported by p-glycoprotein and bcrp at the blood-brain barrier: A small-animal positron emission tomography and in vitro study . Drug Metab. Dispos. 2013, 41, 754-762.

32. Radde, R.; Bolmont, T.; Kaeser, S.A.; Coomaraswamy, J.; Lindau, D.; Stoltze, L.; Calhoun, M.E.; Jaggi, F.; Wolburg, H.; Gengler, S.; et al. Abeta42-driven cerebral amyloidosis in transgenic mice reveals early and robust pathology. EMBO Rep 2006, 7, 940-946.

33. Zoufal, V.; Wanek, T.; Krohn, M.; Mairinger, S.; Filip, T.; Sauberer, M.; Stanek, J.; Pekar, T.; Bauer, M.; Pahnke, J.; et al. Age dependency of cerebral P-glycoprotein function in wild-type and APPPS1 mice measured with PET. J. Cereb. Blood Flow Metab. 2020, 40, 150-162.

34. Allen, J.D.; van Loevezijn, A.; Lakhai, J.M.; van der Valk, M.; van Tellingen, O.; Reid, G.; Schellens, J.H.; Koomen, G.J.; Schinkel, A.H. Potent and specific inhibition of the breast cancer resistance protein multidrug transporter in vitro and in mouse intestine by a novel analogue of fumitremorgin C. Mol. Cancer Ther. 2002, $1,417-425$.

35. Traxl, A.; Wanek, T.; Mairinger, S.; Stanek, J.; Filip, T.; Sauberer, M.; Müller, M.; Kuntner, C.; Langer, O. Breast cancer resistance protein and P-glycoprotein influence in vivo disposition of ${ }^{11} \mathrm{C}$-erlotinib. J. Nucl. Med. 2015, 56, 1930-1936.

36. Linder, M.; Glitzner, E.; Srivatsa, S.; Bakiri, L.; Matsuoka, K.; Shahrouzi, P.; Dumanic, M.; Novoszel, P.; Mohr, T.; Langer, O.; et al. EGFR is required for FOS-dependent bone tumor development via RSK2/CREB signaling. EMBO Mol. Med. 2018, 10, e9408. [CrossRef]

37. Kodaira, H.; Kusuhara, H.; Ushiki, J.; Fuse, E.; Sugiyama, Y. Kinetic analysis of the cooperation of P-glycoprotein (P-gp/Abcb1) and breast cancer resistance protein (Bcrp/Abcg2) in limiting the brain and testis penetration of erlotinib, flavopiridol, and mitoxantrone. J. Pharmacol. Exp. Ther. 2010, 333, 788-796.

38. Hartz, A.M.; Zhong, Y.; Wolf, A.; LeVine, H., 3rd; Miller, D.S.; Bauer, B. Abeta40 reduces P-glycoprotein at the blood-brain barrier through the ubiquitin-proteasome pathway. J. Neurosci. 2016, 36, 1930-1941.

39. Zoufal, V.; Mairinger, S.; Krohn, M.; Wanek, T.; Filip, T.; Sauberer, M.; Stanek, J.; Kuntner, C.; Pahnke, J.; Langer, O. Measurement of cerebral ABCC1 transport activity in wild-type and APP/PS1-21 mice with positron emission tomography. J. Cereb. Blood Flow Metab. 2019, 40, 954-965. 
40. Li, H.C.; Chen, P.Y.; Cheng, H.F.; Kuo, Y.M.; Huang, C.C. In vivo visualization of brain vasculature in Alzheimer's Disease mice by high-frequency micro-Doppler imaging. IEEE Trans. Biomed. Eng. 2019, $66,3393-3401$.

41. Bauer, M.; Wulkersdorfer, B.; Karch, R.; Philippe, C.; Jager, W.; Stanek, J.; Wadsak, W.; Hacker, M.; Zeitlinger, M.; Langer, O. Effect of P-glycoprotein inhibition at the blood-brain barrier on brain distribution of $(R)-\left[{ }^{11}\right.$ C $]$ verapamil in elderly vs. young subjects. Br. J. Clin. Pharmacol. 2017, 83, 1991-1999.

42. Bankstahl, J.P.; Bankstahl, M.; Kuntner, C.; Stanek, J.; Wanek, T.; Meier, M.; Ding, X.; Müller, M.; Langer, O.; Löscher, W. A novel PET imaging protocol identifies seizure-induced regional overactivity of P-glycoprotein at the blood-brain barrier. J. Neurosci. 2011, 31, 8803-8811.

43. Feldmann, M.; Asselin, M.-C.; Liu, J.; Wang, S.; McMahon, A.; Anton-Rodriguez, J.; Walker, M.; Symms, M.; Brown, G.; Hinz, R.; et al. P-glycoprotein expression and function in patients with temporal lobe epilepsy: A case-control study. Lancet Neurol 2013, 12, 777-785.

44. Shin, J.W.; Chu, K.; Shin, S.A.; Jung, K.H.; Lee, S.T.; Lee, Y.S.; Moon, J.; Lee, D.Y.; Lee, J.S.; Lee, D.S.; et al. Clinical applications of simultaneous PET/MR imaging using $(R)-\left[{ }^{11} \mathrm{C}\right]$-verapamil with cyclosporin A: Preliminary results on a surrogate marker of drug-resistant epilepsy. Am. J. Neuroradiol. 2016, 37, 600-606.

45. Mehta, D.C.; Short, J.L.; Nicolazzo, J.A. Altered brain uptake of therapeutics in a triple transgenic mouse model of Alzheimer's disease. Pharm. Res. 2013, 30, 2868-2879.

46. Gustafsson, S.; Lindström, V.; Ingelsson, M.; Hammarlund-Udenaes, M.; Syvänen, S. Intact blood-brain barrier transport of small molecular drugs in animal models of amyloid beta and alpha-synuclein pathology. Neuropharmacology 2018, 128, 482-491.

47. Cheng, Z.; Zhang, J.; Liu, H.; Li, Y.; Zhao, Y.; Yang, E. Central nervous system penetration for small molecule therapeutic agents does not increase in multiple sclerosis- and Alzheimer's disease-related animal models despite reported blood-brain barrier disruption. Drug Metab. Dispos. 2010, 38, 1355-1361.

48. Kalvass, J.C.; Polli, J.W.; Bourdet, D.L.; Feng, B.; Huang, S.M.; Liu, X.; Smith, Q.R.; Zhang, L.K.; Zamek-Gliszczynski, M.J. Why clinical modulation of efflux transport at the human blood-brain barrier is unlikely: The ITC evidence-based position. Clin. Pharmacol. Ther. 2013, 94, 80-94.

49. Wanek, T.; Römermann, K.; Mairinger, S.; Stanek, J.; Sauberer, M.; Filip, T.; Traxl, A.; Kuntner, C.; Pahnke, J.; Bauer, F.; et al. Factors governing p-glycoprotein-mediated drug-drug interactions at the blood-brain barrier measured with positron emission tomography. Mol. Pharm. 2015, 12, 3214-3225.

50. Fox, E.; Bates, S.E. Tariquidar (XR9576): A P-glycoprotein drug efflux pump inhibitor. Expert Rev. Anticancer Ther. 2007, 7, 447-459.

51. Bauer, F.; Kuntner, C.; Bankstahl, J.P.; Wanek, T.; Bankstahl, M.; Stanek, J.; Mairinger, S.; Dörner, B.; Löscher, W.; Müller, M.; et al. Synthesis and in vivo evaluation of $\left[{ }^{11} \mathrm{C}\right]$ tariquidar, a positron emission tomography radiotracer based on a third-generation P-glycoprotein inhibitor. Bioorg. Med. Chem. 2010, 18, 5489-5497.

52. Philippe, C.; Mairinger, S.; Pichler, V.; Stanek, J.; Nics, L.; Mitterhauser, M.; Hacker, M.; Wanek, T.; Langer, O.; Wadsak, W. Comparison of fully-automated radiosyntheses of $\left[{ }^{11} \mathrm{C}\right]$ erlotinib for preclinical and clinical use starting from in target produced $\left[{ }^{11} \mathrm{C}\right] \mathrm{CO}_{2}$ or $\left[{ }^{11} \mathrm{C}\right] \mathrm{CH}_{4}$. EJNMMI Radiopharm. Chem. 2018, 3, 8. [CrossRef]

53. Loening, A.M.; Gambhir, S.S. AMIDE: A free software tool for multimodality medical image analysis. Mol. Imaging 2003, 2, 131-137.

Publisher's Note: MDPI stays neutral with regard to jurisdictional claims in published maps and institutional affiliations.

(C) 2020 by the authors. Licensee MDPI, Basel, Switzerland. This article is an open access article distributed under the terms and conditions of the Creative Commons Attribution (CC BY) license (http://creativecommons.org/licenses/by/4.0/). 